
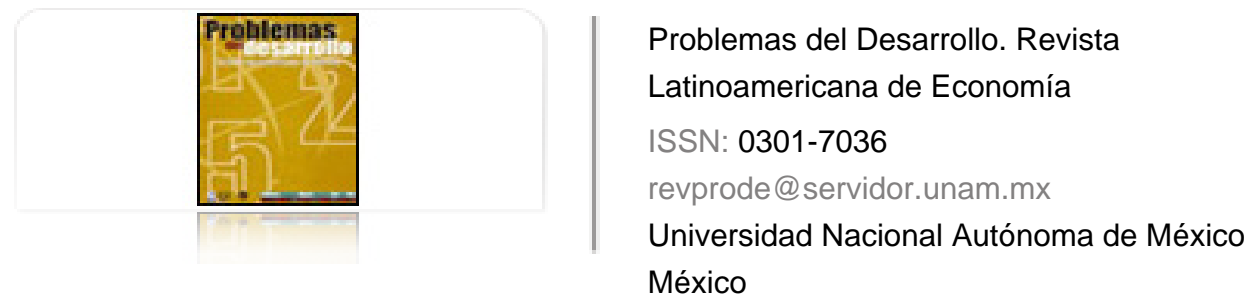

Mansor de Mattos, Fernando Augusto; Dias Carcanholo, Marcelo Amenazas y oportunidades del comercio brasileño con China. Lecciones para Brasil Problemas del Desarrollo. Revista Latinoamericana de Economía, vol. 43, núm. 168, enero-marzo, 2012, pp. 117-145

Universidad Nacional Autónoma de México

Distrito Federal, México

Disponible en: http://www.redalyc.org/articulo.oa?id=11822277006

Cómo citar el artículo

Número completo

- Más información del artículo

Página de la revista en redalyc.org

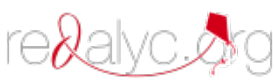

Sistema de Información Científica

Red de Revistas Científicas de América Latina, el Caribe, España y Portugal Proyecto académico sin fines de lucro, desarrollado bajo la iniciativa de acceso abierto 
Revista Problemas del Desarrollo, 168 (43), enero-marzo 2012

\title{
AMENAZAS Y OPORTUNIDADES DEL COMERCIO BRASILEÑO CON CHINA LECCIONES PARA BRASIL
}

\author{
Fernando Augusto Mansor de Mattos y Marcelo Dias Carcanholo*
}

Fecha de recepción: 22 de febrero de 2011. Fecha de aceptación: 7 de agosto de 2011.

\section{RESUMEN}

En 2009, China se convirtió en el principal socio comercial de Brasil. La intensificación de las relaciones comerciales entre ambos países en los últimos años ha provocado rápidos cambios en los resultados agregados y en el perfil de la balanza comercial brasileña. Por un lado, ha permitido una importante expansión de las exportaciones brasileñas, pero muy concentradas en productos de bajo contenido tecnológico, como las materias primas agrícolas y minerales. Por otra parte, se ha producido una fuerte expansión de la participación de productos manufacturados chinos en el mercado interno brasileño, lo que afecta a la producción industrial de Brasil. Además, los datos recogidos en este artículo evidencia que los productos chinos están desplazando a las exportaciones brasileñas de productos manufacturados en los mercados de terceros, en particular en América Latina.

Palabras clave: China, Brasil, comercio externo Brasil-China, exportaciones brasileńas, importaciones brasileńas.

\section{THREATS AND OPPORTUNITES FOR BRAZIL'S TRADE WITH CHINA: LESSONS FOR BRAZIL}

\begin{abstract}
In 2009, China became Brazil's biggest trade partner. The intensification of trading relations between them in the last few years has led to rapid changes in Brazil's aggregate results and in its balance of trade profile. On the one hand, it has permitted a big expansion of Brazilian exports, although these are very concentrated on low technology content products, such as farming raw materials and minerals. On the other hand, it has led to a sharp expansion of the share of Chinese manufactures in Brazil's domestic market, affecting industrial production in Brazil. Also, the data presented in this article provide evidence that China's products are displacing Brazilian manufacturing exports in third markets, especially in Latin America.

Keywords: China; Brazil, Brazil-China foreign trade, Brazilian exports, Brazilian imports.

* Profesores-investigadores en la Facultad de Economía de la Universidad Federal Fluminense (UFF), Brasil. Correo electrónico: fermatt@uol.com.br y mdcarc@uol.com.br
\end{abstract}


Fernando Augusto Mansor de Mattos y Marcelo Dias Carcanholo

\section{MENACES ET ESPOIRS DU COMMERCE BRÉSILIEN AVEC LA CHINE : DES LEÇONS POUR LE BRÉSIL \\ Résumé}

En 2009, la Chine est devenue le principal partenaire du Brésil. L'intensification des relations commerciales entre ces deux pays dans les dernières années a provoqué de rapides changements dans les résultats et le profil de la balance commerciale brésilienne. D'une part, cela a permis une importante expansion des exportations brésiliennes, mais surtout en ce qui concerne les produits de faible contenu technologique, comme les matières premières agricoles et minérales. D'autre part, la participation des produits manufacturés chinois dans le marché interne brésilien s'est fortement accrue, ce qui affecte la production industrielle du Brésil. En outre, les données recueillies dans cet article montrent que les produits chinois supplantent les exportations brésiliennes de produits manufacturés sur les marchés de pays tiers, en particulier en Amérique latine.

Mots clés : Chine, Brésil, commerce extérieur Brésil-Chine, exportations brésiliennes, importations brésiliennes.

\section{AMEAÇAS E OPORTUNIDADES DO COMERCIO BRASILEIRO COM CHINA: LIÇÓES PARA O BRASIL: \\ Resumo}

Em 2009, China se transformou no principal sócio comercial do Brasil. A intensificação das relaçóes comerciais entre eles nos últimos anos provocou rápidas mudanças nos resultados agregados e no perfil da balança de comercial brasileira. Por um lado, permitiu uma importante expansão das exportaçôes brasileiras, como as matérias-primas agrícolas e minerais. Por outra parte, houve uma forte expansão da participaçáo dos produtos manufaturados chineses no mercado interno brasileiro, o que afeta a produção industrial do Brasil. Ademais, os dados apresentados neste capitulo evidenciam que os produtos chineses estão deslocando as exportaçôes brasileiras de manufaturados nos mercados de terceiros, em particular na América Latina.

Palavras-chave: China; Brasil; comércio exterior Brasil-China, exportaçóes brasileiras; importaçóes brasileiras.

中国贸易的威胁和机遇：巴西的经验

摘要:

2009年, 中国成为了巴西第一大贸易伙伴。在过去几年里, 两国贸易关系 的强化使得巴西经济及其贸易平衡发生了急剧变化。一方面，巴西的出口 迅速扩大, 尽管主要集中在低科技含量产品上, 例如, 初级农产品和矿产 品; 另一方面, 中国的制成品在巴西国内市场迅速扩张, 影响了巴西工业 产品的竞争力。此外, 本文的数据表明, 中国的产品在第三方市场也对巴 西的制造业出口构成“排挤”, 特别是在在拉丁美洲市场。

关键词: 中国, 巴西, 巴中贸易, 巴西出口, 巴西进口 


\section{INTRODUCCIÓN}

La reciente evolución del comercio externo brasileño presenta cambios significativos, tanto en lo que se refiere a la rápida reducción del superávit comercial, como en la transformación del perfil de las exportaciones e importaciones según el tipo de producto. ${ }^{1}$ En todas esas transformaciones ocurridas en el comercio externo brasileño, la participación china fue decisiva.

Después de la segunda mitad de 1990, cuando cada año se tenían crecientes déficits comerciales, la economía brasileña empezó a generar vigorosos superávits comerciales, notablemente a partir de 2004, que llegaron a casi 46.5 mil millones de dólares en el 2006. Por otro lado, desde el año 2007 ese superávit descendió rápidamente, más por la trayectoria de las importaciones (que se duplican entre 2006 y 2010) que por las exportaciones que crecen cerca de $46 \%$ en el mismo periodo.

Entre los años 2007 y 2008, las importaciones brasileñas crecieron 23 mil millones de dólares, $44 \%$ de un año al otro. Las importaciones provenientes de China representaron cerca del 15\% de ese crecimiento. Entre 2008 y 2010, a su vez, las importaciones brasileñas aumentaron $5 \%$, algo equivalente a $8.5 \mathrm{mil}$ millones de dólares y la contribución china para ese crecimiento fue de un expresivo $66 \% .^{2}$

1 El perfil del producto será evaluado según su contenido tecnológico. En la primera y segunda secciones del estudio se tomará la clasificación de la CEPAL: a) PRODUCTOS PRIMARIOS, incluyen principalmente alimentos, madera, carbón, petróleo crudo, minerales, etcétera; b) MANUFACTURAS BASADAS EN RECURSOS NATURALES, que incluyen principalmente bebidas, productos en madera, metales básicos (excepto acero), derivados del petróleo, cimiento, piedras preciosas, vidrios etcétera; $c$ ) MANUFACTURAS BASADAS EN BAJA TECNOLOGía que incluyen fundamentalmente productos de la industria textil, manufacturas de cuero y similares, cerámica, muebles, joyería, productos plásticos, etcétera; $d$ ) MANUFACTURAS BASADAS EN MEDIA TECNOLOGía que incluyen, entre otros, vehículos de pasajeros y sus partes, fibras sintéticas, vehículos comerciales en general, motocicletas, productos químicos en general, fertilizantes, plásticos, hierro y acero, maquinaria, motores, máquinas industriales simples, barcos, relojes, etcétera y, finalmente: $e$ ) MANUfACTURAS BASADAS EN ALTA TECNOLOGía, destacando máquinas para procesar datos y computadoras en general, equipos de telecomunicaciones, equipos de televisión, artículos farmacéuticos, turbinas, transistores, aviones, instrumentos ópticos y de precisión, máquinas fotográficas, etcétera.

2 Fuentes: Banco Central de Brasil (www.bcb.gov.br) y Ministerio del Desarrollo, Industria y Comercio Externo (www.mdic.gov.br) 
Fernando Augusto Mansor de Mattos y Marcelo Dias Carcanholo

Respecto al movimiento reciente de las exportaciones también se percibe la significativa presencia china. Entre el valor obtenido en 2007 y el obtenido en 2010 para las exportaciones brasileñas, hubo un salto positivo de cerca de 40 mil millones de dólares, de los cuales 50\% fue por la ampliación de las ventas a China.

La evaluación de la contribución china en los movimientos recientes del comercio externo brasileño permite concluir en una creciente profundización de una nítida "división del trabajo" entre los dos países. En pocas palabras: Brasil exporta a China especialmente commodities agrícolas y minerales, mientras que importa de ese país básicamente productos o materias primas manufacturadas, la mayor parte de elevado valor agregado. En los años más recientes, ese perfil tan nítidamente marcado desde por lo menos la mitad de los años 1990, se ha acentuado de forma aún más significativa. El peso de los productos primarios en el total de la pauta exportadora brasileña para China salió del 68\% en el 2000 a $76 \%$ en 2009 y $83 \%$ en el 2010.

Por otra parte, en los últimos años también ha ocurrido una creciente concentración de la pauta exportadora brasileña direccionada a China en torno a algunos productos específicos. En el 2010, 63\% se concentraba en dos productos (mineral de hierro, soja y derivados), que en 2008 representaban el $57.5 \%$ del total de las exportaciones brasileñas para China. Reuniendo los cinco primeros productos exportados por Brasil a China, había una concentración del 76.3\% de la pauta en el 2008 y $82.6 \%$ en 2010. La pauta de importaciones provenientes de China, a su vez, siempre fue más diversificada, además de direccionada a productos manufacturados de elevado o mediano grado de incorporación tecnológica. En 2008, los cinco principales productos importados por Brasil de China representaban $12.45 \%$ de las importaciones provenientes de aquel país; en $2010,10.85 \% .^{3}$

Además, se debe subrayar que la mayor diversificación ocurrida entre los principales productos importados de China se dio al mismo tiempo en que aumentó la participación de productos provenientes de aquel país a Brasil entre el año 2000 (cuando las importaciones chinas eran apenas el 2.2\% del total) y al año $2010(14.5 \%)$.

3 Datos obtenidos con informaciones divulgadas en el sitio del Ministerio del Desarrollo, Industria y Comercio Externo del Brasil (www.mdic.gov.br), Baumann et al. (2010) también demuestran esta situación con base en indicadores de participación de productos en la pauta exportadora para China en el rubro de importaciones provenientes de ella. En el referido estudio, los autores muestran que situación similar ocurre en relación a India y Rusia. 
De manera general, los datos del 2010 demuestran una profundización de los movimientos que empezaron en $2008,{ }^{4}$ encendiendo la alerta para las autoridades económicas brasileñas con respecto a la dificultad de sostener la balanza comercial en superávit por más tiempo, en caso de que el tipo de cambio se mantuviera en la trayectoria actual de valorización. Datos recientes revelan que si no fuese la continua recuperación de los precios de las commodities, Brasil podría haber obtenido un déficit comercial ya en 2010, profundizando aún más el déficit en cuenta corriente. ${ }^{5}$

En este contexto reciente, una vez más, la presencia china fue decisiva. Según la FUNCEX, ${ }^{6}$ los términos de cambio mejoraron cerca del $16 \%$ en 2010 , más que lo acumulado entre 2004 y 2008 (que fue de 13.9\%). Esto se explica por el crecimiento favorable de los precios de commodities, en un contexto de gran crecimiento de la demanda china y de extremada abundancia de liquidez internacional, en buena medida explicada por las medidas elaboradas por los países desarrollados para combatir la crisis económica y financiera que aún sufrimos.

Considerando todo eso se justifica un estudio más preciso acerca de los efectos que el comercio externo brasileño ha sufrido mediante la profundización de las relaciones comerciales con China. Esos efectos deben ser evaluados en términos de los cambios en el perfil de las exportaciones e importaciones brasileńas con respecto a China, con efectos también sobre el conjunto de importaciones y exportaciones brasileñas, una vez que el flujo comercial con

4 Los datos de 2008, comparados al 2007, muestran que hubo un crecimiento de cerca de $44 \%$ en las importaciones y de apenas $23 \%$ en las exportaciones. El superávit comercial de 2007 fue de 40,032 mil millones de dólares y, en el 2008, había disminuido a 24,8 mil millones de dólares, manteniendo este nivel en 2009 (25,3 mil millones de dólares), sólo por el carácter atípico de la crisis, cayendo nuevamente en el 2010 para 20,2 mil millones de dólares.

5 Datos divulgados en las series históricas del Banco Central de Brasil (www.bcb.gov.br) muestran que en 2005 y en 2006, el saldo en cuenta corriente brasileńo estaba en torno a los 13 mil millones de dólares, disminuyendo para sólo 1,5 mil millones de dólares en 2007; en 2008 se puso acentuadamente negativo ( 28 mil millones de dólares), manteniéndose un poco menos deficitario en 2009 (24,3 mil millones de dólares), seguramente en razón de la crisis y la retracción de la economía brasileña. El año 2010 terminó con un déficit de cerca de 47,5 mil millones de dólares.

6 La Fundación Centro de Estudios del Comercio Externo es una institución privada brasileña que tiene el objetivo de desarrollar estudios para el desarrollo del comercio externo del país. Cf. (www.funcex.com.br). La base de datos estadísticos, en www.funcexdata.com.br. 
China es no solamente muy significativo como también presenta tasas crecientes de expansión. ${ }^{7}$

Para cumplir el objetivo de estudiar el impacto de la expansión del comercio exterior chino sobre el comercio exterior brasileño, este trabajo se divide en 4 partes además de esta introducción; en la primera, se describe en líneas generales la evolución reciente del comercio externo chino, evaluando su crecimiento en otras regiones/países, y también los cambios ocurridos en los perfiles de sus exportaciones e importaciones según la categoría del producto. En esta primera parte también se describen las crecientes relaciones comerciales de China con América Latina, lo que abre el camino para que, en la siguiente parte, se puedan interpretar los efectos de esa mayor integración sobre el comercio externo de Brasil con la propia China y también con otros países/bloques económicos. En la segunda parte se analizan las respectivas evoluciones del perfil de las exportaciones y las importaciones brasileñas comparando las informaciones de regiones de destino/origen y las de categoría de productos, entre 1990 y 2008, destacando en cada caso el papel de China en comparación con las demás regiones del mundo. En la tercera parte se analizan resultados que destacan los principales efectos de la expansión del comercio externo chino sobre la actividad industrial brasileña, con base en la observación de la presencia de los productos chinos en la estructura de importaciones de Brasil, evaluada según la intensidad de factores incorporados a los productos. ${ }^{8}$ La cuarta parte muestra evidencias de que el avance de las exportaciones chinas ha competido con exportaciones brasileñas en otros mercados.

Se debe registrar que las trayectorias distintas de las exportaciones chinas, en comparación con las de Brasil y demás países latinoamericanos se explican decididamente por el contenido y la extensión de las reformas estructurales ocurridas en la economía china desde el final de los años 1970. Lo esencial de aquellas medidas fue fundamentalmente la definición de instrumentos de intervención

7 En 2009 China se volvió el principal destino de las exportaciones brasileñas. En el 2005, por ejemplo, China era el tercer principal destino de las exportaciones brasileńas $y$, en 2000, era apenas el décimo segundo. En lo que se refiere a las importaciones también hubo un aumento de la importancia de China: en el año 2000 China estaba en undécimo puesto, en 2005 había subido para el cuarto, y llega en 2009 a segundo.

8 Los productos son clasificados como intensivos en recursos naturales, intensivos en trabajo, intensivos en escala e intensivos en tecnología. Esa clasificación fue utilizada por Puga e Nascimento (2010) con base en datos del Ministerio de Desarrollo, Industria e Comercio Externo de Brasil. 
del Estado9 para promover las exportaciones chinas rumbo a bienes industriales de alto contenido tecnológico. En los años 1990, las diferencias entre China y la mayoría de los países latinoamericanos se profundizan, pues estos últimos adoptaron políticas neoliberales de inserción en el llamado proceso de globalización. En China, al revés, ese proceso fue reforzado por la ampliación de las inversiones públicas volcadas al mercado interno, por la creación de las zonas especiales direccionadas para la promoción del progreso técnico contenido en los productos exportados, y por la expansión de las inversiones públicas en infraestructura (con mayor énfasis en los dos últimos años, 2009 y 2010, después de la desaceleración de la economía mundial en el periodo siguiente a la crisis del subprime $)^{10}$ y por el mantenimiento, bajo control del Estado chino, de las empresas estatales consideradas estratégicas para el desarrollo industrial y la obtención estructural de productividad en la agricultura.

\section{EVOLUCIÓN RECIENTE DEL COMERCIO EXTERNO CHINO ${ }^{11}$}

Según datos recientes de la CePAL (2010: 09), China superó en la última década a Alemania en el ranking de exportaciones mundiales, y también se ha convertido en el mayor exportador mundial de bienes. En 2009 China tenía el

9 Lo que incluye además de otros factores, la institucionalización de las zonas especiales de exportación (Oliveira, 2005; Felipe, 2009), la opción por una política cambiaria que favorezca las exportaciones (Medeiros, 2006; 2010), la ampliación de la integración industrial y, por lo tanto, también comercial con los demás países asiáticos más importantes (Medeiros, 2006; 2010; Pasin, 2008; Sawaya, 2011), la ampliación de las inversiones públicas en Ciencia y Tecnología (Oliveira, 2005; Medeiros, 2006; Tepassê e Carvalho, 2010), la expansión de las inversiones públicas en infraestructura (Medeiros, 2010), al mismo tiempo en que buscaba impulsar sectores estratégicos para lograr esas inversiones, como por ejemplo, la industria siderúrgica que ha promovido un intenso cambio en el comercio externo chino, debido al aumento significativo de la producción interna de acero y hierro, con ampliación de la importación de mineral de hierro, insumo fundamental para su creciente industria siderúrgica, como pone de relieve Pasin (2008).

10 Según Medeiros (2010), una de las principales medidas tomadas por el gobierno chino como respuesta a la crisis internacional, con el objetivo de impulsar el mercado interno, compensando la pérdida de demanda por sus exportaciones, fue un paquete de inversiones públicas en infraestructura con una magnitud cercana a quinientos mil millones de dólares.

11 Los datos presentados en los Cuadros 1 y 2 fueron obtenidos en el sitio de la CEPAL (http:// www.eclac.org/comercio/serieCP/eclactrade/serie_101_comercio_total_tiempo_content. html). Para datos de China ver serie 101. Están disponibles informaciones hasta el ańo 2009 (acceso en el 18/08/2011). 
Fernando Augusto Mansor de Mattos y Marcelo Dias Carcanholo

10\% de las exportaciones mundiales que llegaban a 12,460 billones de dólares. Alemania, por su parte, tenía el 9\% y los Estados Unidos el 8\%. Esas participaciones en el año 2000 eran muy diferentes (4\%, 9\% y 12\%, respectivamente, para un total de 6,380 billones de dólares). Esto quiere decir que China logró un aumento en 6 puntos porcentuales dentro de un valor del comercio internacional que ha doblado en apenas 9 años. ${ }^{12}$ Ese dinamismo puede ser mejor analizado si se realiza según el punto de vista de los cambios en la estructura de las exportaciones por categoría de producto.

Los datos del Cuadro 1 muestran claramente la reducción porcentual de los productos primarios en el total de las exportaciones. Ellos representaban 20.15\% en 1990 , disminuyen para $9.0 \%$ en $1995,6.2 \%$ en 2000 y llegan a $2.3 \%$ y $2.5 \%$ en 2008 y 2009. Las exportaciones de manufacturas de media y alta tecnología, que significaban $26.18 \%$ del total de exportaciones en 1990 , pasan $31.8 \%$ en 1995 , 42\% en 2000, llegan al 56\% en 2007/2008 y, en 2009, obtienen el 58\%. Claramente a lo largo del periodo las exportaciones chinas tienen una concentración en productos manufacturados de media y alta tecnología, en detrimento de los productos primarios, no olvidando que ese proceso ocurre al mismo tiempo que la trayectoria de fuerte crecimiento del total de exportaciones del país.

Cuadro 1: Exportaciones chinas de bienes por categoría de producto (\%)

\begin{tabular}{lrrrrrr}
\hline & 1990 & 1995 & 2000 & 2007 & 2008 & 2009 \\
\hline Productos primarios & 20.15 & 9.01 & 6.20 & 2.30 & 2.36 & 2.49 \\
Manufacturas basadas en recursos naturales & 11.43 & 12.05 & 9.89 & 9.33 & 9.73 & 8.81 \\
Manufacturas de baja tecnología & 40.16 & 46.34 & 41.21 & 30.99 & 30.53 & 30.11 \\
Manufacturas de media tecnología & 20.84 & 18.85 & 19.64 & 23.29 & 24.66 & 23.53 \\
Manufacturas de alta tecnología & 5.35 & 13.01 & 22.39 & 33.60 & 32.28 & 34.55 \\
Otras transacciones & 2.07 & 0.67 & 0.67 & 0.49 & 0.44 & 0.51 \\
\hline
\end{tabular}

Fuente: SIGCI-CEPAL

12 En términos absolutos, los valores de las exportaciones chinas, que en el 1990 eran de 62 mil millones de dólares, pasan a 149 mil millones de dólares en el 1995 y 249 mil millones de dólares en el 2000. En este siglo, la tasa de crecimiento de las exportaciones sube, y el total de éstas en el 2007 llega a 1,220 mil millones de dólares, y 1,430 mil millones de dólares el año siguiente. La caída para 1,201 mil millones de dólares en el 2009 se debe al momento coyuntural desfavorable, en razón de los efectos retrasados de la crisis del 2007-2008 en la economía mundial. El mismo patrón se percibe en las importaciones. De un total de 53 mil millones de dólares en el 1990, ellas pasan a 132 mil millones de dólares en el 1995, 225 mil millones de dólares en el 2000, aceleran el crecimiento para llegar a 956 mil millones de dólares en el 2007, y 1,132 mil millones de dólares al ańo siguiente. La disminución para 1,005 mil millones de dólares un año después también se explica por los efectos de la crisis en la economía mundial. 
Hubo también cambios significativos en la estructura de las importaciones chinas, como se ve en el Cuadro 2, que muestran un crecimiento de los productos primarios (10.8\% del total en 1990 y de $22 \%$ en 2009) al mismo tiempo que los bienes manufacturados de alta tecnología (13.4\% en 1990 y $32 \%$ en 2009). Esta última ampliación revela un cambio del sector productivo chino en el periodo hacia una estructura industrial más compleja ${ }^{13}$ (Medeiros, 2006).

Del punto de vista de los destinos de las exportaciones chinas y de los orígenes de sus importaciones, datos recientes de la CEPAL ${ }^{14}$ revelan una creciente importancia del conjunto de América Latina y El Caribe. Según esos datos, la tasa de crecimiento de las exportaciones chinas con destino a América Latina y El Caribe es superior a la tasa de crecimiento de las exportaciones chinas que tienen como destino toda la economía mundial desde 1990 hasta el momento actual, revelando una demanda vigorosa y estable de los países de nuestro continente por los productos chinos. ${ }^{15}$

Cuadro 2: Importaciones chinas de bienes por categoría de producto (\%)

\begin{tabular}{lrrrrrr}
\hline & 1990 & 1995 & 2000 & 2007 & 2008 & 2009 \\
\hline Productos primarios & 10.78 & 10.33 & 13.70 & 18.84 & 24.66 & 22.01 \\
Manufacturas basadas en recursos naturales & 11.90 & 13.91 & 15.21 & 14.03 & 14.11 & 14.48 \\
Manufacturas de baja tecnología & 17.03 & 14.94 & 11.55 & 6.40 & 5.78 & 5.71 \\
Manufacturas de media tecnología & 45.93 & 42.05 & 30.37 & 25.23 & 23.86 & 25.30 \\
Manufacturas de alta tecnología & 13.41 & 17.42 & 28.04 & 34.98 & 30.97 & 31.90 \\
Otras transacciones & 0.96 & 0.99 & 1.13 & 0.51 & 0.62 & 0.61 \\
\hline
\end{tabular}

Fuente: SIGCI-CEPAL.

13 Tal comportamiento de las importaciones chinas, más allá de revelar la instalación de un parque industrial más complejo, muestra también una ampliación de las actividades industriales en general, que demandan crecientes cantidades de materias primas (desde commodities hasta bienes manufacturados basados en recursos naturales). Además de eso, la naturaleza y la magnitud de la expansión de las importaciones chinas también resultan de las transformaciones urbanas por las cuales viene pasando la sociedad china (Oliveira, 2005; Medeiros, 2006), que se manifiestan en aumento de la urbanización, crecimiento del ingreso medio y cambio de los patrones de consumo.

14 Cf. CePAL (2010: 08).

15 En la primera década de este siglo en particular, las exportaciones chinas para América Latina y El Caribe tuvieron un promedio de crecimiento anual dos veces mayor que las exportaciones chinas para el promedio de la economía mundial. 
Fernando Augusto Mansor de Mattos y Marcelo Dias Carcanholo

Esos mismos datos de la CEPAL ${ }^{16}$ también muestran que, desde la segunda mitad de la década de 1990, las importaciones chinas de productos provenientes de América Latina y El Caribe presentan continuamente una tasa de crecimiento superior a la del promedio mundial y, desde la primera década de este siglo, mayor que la de todas las regiones del mundo.

Basada en estas líneas generales sobre la evolución y la estructura de China, la cuestión que se plantea es cómo esa nueva realidad afecta las exportaciones brasileñas, especialmente de los productos manufacturados.

\section{EVOLUCIÓN DE LA ESTRUCTURA DEL COMERCIO EXTERNO BRASILEÑO POR TIPO DE PRODUCTO Y LA INFLUENCIA CHINA ${ }^{\text {I7 }}$}

El Cuadro 3 compara el perfil de las exportaciones brasileñas por destino y por tipo de producto en 1990 y 2008. Es posible percibir un cambio radical en el perfil del comercio brasileño con China, en comparación con otras regiones. ${ }^{18}$ Los datos revelan que sólo el 1.2\% del total de las exportaciones brasileñas de 1990 tenían como destino China, mientras que en 2008 ese porcentual era de $8.3 \%$.

Sus datos muestran también que en 1990, 28.1\% de las exportaciones brasileñas eran de productos primarios, y en 2008 ese porcentual era igual a $38.3 \%$, o sea, hubo un aumento de 10.2 puntos porcentuales en la participación de productos primarios en las exportaciones brasileñas, de manera que la contribución de China como destino de ese tipo de productos fue de 6.2 puntos (Cuadro 3). Vistos de otra forma, los datos revelan que casi el $90 \%$ del aumento de la participación de China como destino de las exportaciones brasileñas se explica por la demanda china por productos primarios y, el restante, en casi su totalidad se debió a bienes industrializados basados en recursos naturales. La ampliación de la presencia china como destino de las exportaciones de Brasil ha representado un desplazamiento de la posición que en 1990 era representada por Japón como principal destino en Asia de las exportaciones brasileñas. China superaba como

16 Cf. CePal (2010:08).

17 Los Cuadros 3 y 4 se pueden obtener en: http://www.eclac.org/cgi-bin/getprod.asp?xml=/ comercio/noticias/paginas/2/21312/P21312.xml\&xsl=/comercio/tpl/p18f.xsl\&base=/comercio/tpl/top-bottom.xsl

18 Decidimos eliminar de este análisis el atípico año de 2009, pues fue el año más agudo de la crisis surgida con el colapso del sistema de financiamiento inmobiliario del subprime americano. Los datos del 2010 aún no están disponibles en esta base de datos. Eso no nos impide, entretanto, observar los cambios tendenciales revelados desde el inicio de la década de 1990. 
Amenazas y oportunidades del comercio brasileño con China

Cuadro 3. Perfil y destino de las exportaciones brasileñas

\begin{tabular}{|c|c|c|c|c|c|c|c|c|}
\hline BRASIL 1990 & $A L C$ & EEUU & UE & ASIA 16 & CHINA & JAPÓN & OTROS & TOTAL \\
\hline \multicolumn{9}{|l|}{ EXPORTACIONES } \\
\hline Productos primarios & 1.1 & 3.2 & 15.0 & 1.9 & 0.2 & 3.2 & 3.4 & 28.1 \\
\hline Bienes industrializados & 10.5 & 21.4 & 18.5 & 6.7 & 1.0 & 4.2 & 8.4 & 70.6 \\
\hline Basados en recursos naturales & 2.2 & 7.4 & 8.5 & 1.1 & 0.4 & 2.4 & 3.8 & 25.9 \\
\hline De baja tecnología & 1.6 & 5.1 & 3.6 & 2.0 & 0.2 & 0.4 & 1.8 & 14.7 \\
\hline De tecnología media & 5.6 & 7.1 & 5.4 & 3.4 & 0.4 & 1.4 & 2.5 & 25.7 \\
\hline De alta tecnología & 1.0 & 1.9 & 1.0 & 0.2 & 0.0 & 0.1 & 0.2 & 4.3 \\
\hline Otras transacciones & 0.0 & 0.0 & 0.1 & 0.0 & 0.0 & 0.0 & 1.2 & 1.3 \\
\hline Total & 11.6 & 24.6 & 33.6 & 8.5 & 1.2 & 7.5 & 13.0 & 100.0 \\
\hline BRASIL 2008 & $A L C$ & EEUU & UE & ASIA 16 & CHINA & JAPÓN & OTROS & TOTAL \\
\hline \multicolumn{9}{|l|}{ EXPORTACIONES } \\
\hline Productos primarios & 5.1 & 3.3 & 10.9 & 3.5 & 6.4 & 2.1 & 7.0 & 38.3 \\
\hline Bienes industrializados & 20.1 & 10.4 & 12.4 & 4.3 & 1.9 & 1.0 & 8.7 & 58.7 \\
\hline Basados en recursos naturales & 3.9 & 3.0 & 6.0 & 1.1 & 1.0 & 0.6 & 4.8 & 20.4 \\
\hline De baja tecnología & 2.7 & 1.3 & 1.6 & 0.4 & 0.2 & 0.1 & 0.6 & 6.9 \\
\hline De tecnología media & 11.0 & 4.1 & 3.8 & 2.3 & 0.5 & 0.3 & 2.5 & 24.5 \\
\hline De alta tecnología & 2.5 & 2.0 & 1.0 & 0.5 & 0.2 & 0.0 & 0.7 & 6.9 \\
\hline Otras Transacciones & 0.1 & 0.3 & 0.2 & 0.0 & 0.0 & 0.0 & 2.5 & 3.0 \\
\hline Total & 25.2 & 14.0 & 23.5 & 7.8 & 8.3 & 3.1 & 18.1 & 100.0 \\
\hline
\end{tabular}

Fuente: CEPAL, con base de datos oficiales.

destino en 2008, hasta el agregado de 16 países ${ }^{19}$ de Asia-Pacífico (8.3\% del total de las exportaciones brasileñas tenían como destino, en aquel año, China, contra 7.8\% del conjunto de 16 países asiáticos aquí definidos).

19 El sitio destacado antes provee las notas metodológicas que se refieren a estos datos (ver: http://www.eclac.org/cgi-bin/getprod.asp?xml=/comercio/noticias/paginas/2/21312/ P21312.xml\&xsl=/comercio/tpl/p18f.xsl\&base=/comercio/tpl/top-bottom.xsl). Para los 16 países de Asia que constituyen el agregado Asia 16, las notas indican un conjunto de 15 países (ni todos asiáticos de hecho) más uno denominado "otros países de Asia no especificados". Los 15 países mencionados, que hacen parte del bloque para efecto de análisis de comercio externo del documento, son: Australia, Brunei Darussalam, Camboya, Filipinas, Hong Kong (región administrativa especial de China), India, Indonesia, República Democrática Popular del Lao (Laos), Malasia, Myanmar, Nueva Zelandia, República de Corea, Singapur, Tailandia y Vietnam. Los datos referentes a Japón y China son evaluados separadamente, por la importancia individual de cada uno de ellos. 
El Cuadro 3 muestra todavía que los 16 países asiáticos seleccionados también tuvieron una importante contribución para la ampliación de las exportaciones de productos primarios brasileños. En términos de destino se observó, en el caso brasileño, una reducción de la importancia de eEuU y de la Unión Europea $^{20}$ de 10 puntos porcentuales para cada uno de ellos ${ }^{21}$ entre 1990 y 2008. La disminución del comercio con eEuU y Unión Europea es preocupante en la medida en que los dos, en 1990, eran responsables, en conjunto, de casi la mitad de las exportaciones brasileñas de bienes industrializados de media y de alta tecnología. Por otro lado, se debe realzar que la ampliación de la participación relativa de países del continente latinoamericano como destino de las exportaciones brasileñas parece estar especialmente basada en la absorción, por parte de esos países, de productos manufacturados de media tecnología (principalmente) y de alta tecnología, sugiriendo que el comercio con esos países puede ser una alternativa importante para la exportación de productos de mayor valor agregado por parte de Brasil. 22

La estructura de las importaciones brasileñas, a su vez, sufrió básicamente dos cambios expresivos en su trayectoria entre 1990 y 2008 (Cuadro 4), y aquí también la contribución del comercio con China fue decisiva, saliendo de apenas $0.9 \%$ para $11.6 \%$.

20 Según publicación de metodología de la CEPAL: Alemania, Austria, Bélgica, Bulgaria, Chipre, Dinamarca, Eslovaquia, Eslovenia, España, Estonia, Finlandia, Francia, Grecia, Hungría, Irlanda, Italia, Letonia, Lituania, Luxemburgo, Malta, Países Bajos, Polonia, Portugal, Reino Unido, República Checa, Rumanía y Suecia.

21 En 1990, según datos que originaron los Cuadros, 24.6\% de las exportaciones brasileńas se destinaban a EEUU y, en 2008, sólo 14\%. Con respecto a la Unión Europea, las cifras son iguales a $33.6 \%$ y $23.5 \%$ respectivamente. En los dos últimos ańos, esas cifras cayeron aún más, pues la crisis internacional viene afectando especialmente los países más desarrollados.

22 En lo que se refiere a los bienes industrializados de media tecnología, América Latina y El Caribe representan el único destino comercial para el cual hubo aumento de la participación relativa de las exportaciones brasileńas entre 1990 y 2008 (5.4 puntos porcentuales), lo que no evitó una caída de la participación de las exportaciones de ese tipo de producto en el conjunto de las exportaciones brasileñas en el periodo (caída de 1.2 punto porcentual). En el caso de los bienes industrializados de alta tecnología hubo un aumento de 2.6 puntos porcentuales en su participación en el total de exportaciones brasileńas, de los cuales 1.5 punto se debió exclusivamente al continente latinoamericano (y Caribe), lo que demuestra la importancia creciente de esos países como compradores de productos brasileños de mayor contenido tecnológico en los últimos veinte años. 
Desde el punto de vista del tipo de producto, hubo una expansión de la presencia en las importaciones brasileñas de bienes manufacturados de medio y de alto grado de incorporación tecnológica, teniendo como contrapartida una expresiva caída de la participación relativa de productos primarios. Se debe subrayar que esos dos movimientos tuvieron gran contribución de productos provenientes de China. La expansión de la presencia de productos chinos se debió, principalmente, a bienes manufacturados de media y alta tecnología (sumando 7.5 puntos porcentuales en un total de 10.7 puntos porcentuales, lo que representó un aumento, entre 1990 y 2008, en la participación de las importaciones chinas); igualmente, observando los datos de otra forma, se percibe un aumento de cerca de 13.4 puntos porcentuales (entre 1990 y 2008) de la suma entre bienes manufacturados de media y de alta tecnología en las importaciones brasileñas (Cuadro 4). De ese total, casi $55 \%$ (o sea, 7.5 puntos porcentuales) se debió a productos provenientes de China, lo que también revela la importancia de la contribución china para el cambio en la estructura importadora brasileña en las dos últimas décadas.

Cuadro 4. Perfil y origen de las importaciones brasileñas

\begin{tabular}{lllllllll}
\hline BRASIL 1990 & ALC & EEUU & UE & ASIA 16 & CHINA & JAPÓN & OTROS & TOTAL \\
\hline IMPORTACIONES & & & & & & & & \\
Productos primarios & 7.3 & 2.5 & 1.4 & 0.9 & 0.5 & 0.0 & 22.6 & 35.2 \\
Bienes industrializados & 10.3 & 17.4 & 21.1 & 1.7 & 0.4 & 7.1 & 6.2 & 64.3 \\
Basados en recursos naturales & 5.5 & 3.3 & 4.8 & 0.3 & 0.2 & 0.6 & 2.5 & 17.0 \\
De baja tecnología & 1.6 & 1.2 & 1.7 & 0.3 & 0.1 & 0.6 & 0.3 & 5.7 \\
De tecnología media & 2.4 & 7.6 & 10.8 & 0.6 & 0.1 & 2.9 & 2.7 & 27.1 \\
De alta tecnología & 0.8 & 5.4 & 3.8 & 0.5 & 0.1 & 3.1 & 0.8 & 14.4 \\
Otras Transacciones & 0.1 & 0.2 & 0.2 & 0.0 & 0.0 & 0.0 & 0.0 & 0.5 \\
Total & 17.7 & 20.1 & 22.7 & 2.6 & 0.9 & 7.2 & 28.8 & 100.0 \\
\hline BRASIL 2008 & ALC & EEUU & UE & ASIA 16 & CHINA & JAPÓN & 0 OTROS & TOTAL \\
\hline IMPORTACIONES & & & & & & & & \\
Productos primarios & 4.9 & 1.1 & 0.4 & 1.1 & 0.2 & 0.0 & 10.8 & 18.5 \\
Bienes industrializados & 11.4 & 13.8 & 20.4 & 11.2 & 11.4 & 3.9 & 9.2 & 81.3 \\
Basados en recursos naturales & 4.5 & 2.9 & 3.9 & 2.7 & 1.5 & 0.4 & 2.8 & 18.7 \\
De baja tecnología & 0.7 & 0.9 & 1.8 & 1.3 & 2.2 & 0.3 & 0.4 & 7.7 \\
De tecnología media & 5.5 & 6.7 & 10.4 & 2.8 & 3.0 & 2.3 & 5.2 & 36.0 \\
De alta tecnología & 0.8 & 3.2 & 4.2 & 4.3 & 4.7 & 0.9 & 0.8 & 18.9 \\
Otras Transacciones & 0.0 & 0.0 & 0.1 & 0.0 & 0.0 & 0.0 & 0.0 & 0.2 \\
Total & 16.4 & 14.9 & 20.9 & 12.3 & 11.6 & 3.9 & 20.0 & 100.0 \\
\hline
\end{tabular}

Fuente: CEPAL, con base de datos oficiales. 
Fernando Augusto Mansor de Mattos y Marcelo Dias Carcanholo

\section{EFECTOS DE LA EXPANSIÓN DEL COMERCIO EXTERNO CHINO SOBRE LA PRODUCCIÓN INDUSTRIAL BRASILEÑA}

Conforme apuntamos en la introducción, la participación china en las importaciones brasileñas aumenta expresivamente en los últimos años. En 1990, la participación china era de cerca de $1.2 \%$, y ese porcentual saltó para $8.5 \%$ en 2008 y $14.5 \%$ dos años después. Más destacable aún es el rápido y nítido cambio en la estructura de los productos importados provenientes de China en los años más recientes. Hace algunas décadas, la mayor parte de los importados chinos que llegaban a Brasil estaba formada por productos intensivos en trabajo. En los años más recientes, eso sufrió una transformación significativa, con efectos especialmente sobre la producción interna de las actividades de algunos segmentos industriales domésticos en Brasil.

El Cuadro 5 muestra la evolución de los valores en dólares de las importaciones brasileñas entre 2005 y 2010 realzando también la evolución de la parcela de China en las importaciones, según cuatro tipos de productos y diversos sectores de actividades (Puga y Nascimento, 2010). En la última columna se encuentran expresados los valores de la variación de la participación de China, en puntos porcentuales, entre 2005 y 2010, para cada tipo de producto.

En primer lugar, se debe realzar que en el periodo en cuestión, las importaciones brasileñas crecieron notablemente en todos los tipos de productos (intensivos en recursos naturales, intensivos en trabajo, intensivos en escala e intensivos en tecnología) y, en todos estos cuatro casos, el aumento de la participación china fue expresivo, marcadamente en los sectores industriales intensivos en trabajo (en los cuales la participación de las importaciones chinas siempre fue mayor que los demás) y los intensivos en tecnología. En el caso de los intensivos en trabajo, el porcentual subió 14.8 puntos, es decir, pasó de 24.3\% (en 2005) para 39.1\% (en 2010), y, en los sectores intensivos en tecnología, subió 11.0 puntos porcentuales, creciendo de $15.4 \%$ a $26.4 \%$ (Cuadro 5).

Esa expansión de la participación de los productos chinos en las importaciones brasileñas no debe ser interpretada de forma aislada, pero principalmente, por el efecto de la misma sobre la producción industrial doméstica, por sus efectos en términos de sustitución del consumo de la producción doméstica por productos originariamente producidos en el exterior y, en particular, en China. En ese sentido, Puga y Nascimento (2010) se sirven de los conceptos de coeficiente de importación y de consumo aparente. ${ }^{23}$ Los autores buscan interpretar cuál es

23 Como recuerdan Puga y Nascimento (2010), "el coeficiente de importación mide la participación de las importaciones en el consumo aparente doméstico de cada sector (...) El consumo aparente es medido por el total de la producción interna, disminuida de las ventas externas (exportaciones) y sumada a las importaciones". 
Amenazas y oportunidades del comercio brasileño con China

Cuadro 5. Importaciones brasileñas por origen e intensidad de factores

US\$ millones

\begin{tabular}{|c|c|c|c|c|c|c|c|}
\hline & \multicolumn{3}{|c|}{2005} & \multicolumn{3}{|c|}{2010} & \multirow{2}{*}{$\begin{array}{l}\text { Var. en la } \\
\text { Particip. } \\
\text { de China } \\
\text { (en p.p.). }\end{array}$} \\
\hline & total & China & \% China & total & China & \% China & \\
\hline INTENSIVOS EN RECURSOS NATURALES & 18439 & 311 & 1.7 & 37696 & 893 & 2.4 & 0.7 \\
\hline Extractiva & 10911 & 34 & 0.3 & 17599 & 23 & 0.1 & -0.2 \\
\hline Madera & 4007 & 168 & 4.2 & 11983 & 187 & 1.6 & -2.6 \\
\hline Alimentos y combustibles & 1999 & 32 & 1.6 & 5004 & 208 & 4.2 & 2.6 \\
\hline Prod. Madera & 85 & 4 & 5.2 & 122 & 19 & 15.8 & 10.6 \\
\hline Papel y celulosa & 868 & 4 & 0.5 & 1692 & 86 & 5.1 & 4.6 \\
\hline Prod. minerales no metálicos & 569 & 68 & 12 & 1296 & 369 & 28.5 & 16.5 \\
\hline INTENSIVOS EN TRABAJO & 3107 & 755 & 24.3 & 8833 & 3450 & 39.1 & 14.8 \\
\hline Textil & 881 & 231 & 26.2 & 2896 & 1224 & 42.3 & 16.1 \\
\hline Vestimenta & 225 & 106 & 46.9 & 898 & 545 & 60.7 & 13.8 \\
\hline Cueros y calzados & 333 & 146 & 43.9 & 751 & 370 & 49.3 & 5.4 \\
\hline Prod. de metal & 1249 & 99 & 7.9 & 2987 & 558 & 18.7 & 10.8 \\
\hline Muebles diversos & 420 & 173 & 41.2 & 1301 & 754 & 57.9 & 16.7 \\
\hline INTENSIVOS EN ESCALA & 25304 & 905 & 3.6 & 60614 & 4148 & 6.8 & 3.2 \\
\hline Químicos & 14957 & 639 & 4.3 & 30624 & 2065 & 6.7 & 2.4 \\
\hline Caucho y plástico & 2174 & 111 & 5.1 & 4825 & 552 & 11.4 & 6.3 \\
\hline Metalurgia básica & 2930 & 109 & 3.7 & 8206 & 1124 & 13.7 & 10.0 \\
\hline Vehículos & 5243 & 46 & 0.9 & 16959 & 407 & 2.4 & 1.5 \\
\hline INTENSIVOS EN TECNOLOGÍA & 29403 & 4515 & 15.4 & 59080 & 15616 & 26.4 & 11.0 \\
\hline Máquinas y equipos & 7562 & 366 & 4.8 & 17393 & 2590 & 14.9 & 10.1 \\
\hline Material eléctrico & 7125 & 1626 & 22.8 & 12530 & 4893 & 39.0 & 16.2 \\
\hline Electrónicos & 12145 & 2458 & 20.2 & 23527 & 7894 & 33.6 & 13.4 \\
\hline Otros equip. transporte & 2572 & 66 & 2.6 & 5640 & 239 & 4.2 & 1.6 \\
\hline TOTAL & 76253 & 6487 & 8.5 & 166223 & 24206 & 14.5 & 6.0 \\
\hline
\end{tabular}

Fuente: CEXEC. Elaboración: APE/BNDES. Apud: Puga y Nascimento (2010). 
la sustitución del consumo de bienes producidos en el mercado interno por bienes producidos en el exterior y después, en particular, por bienes producidos en China, con el objetivo de evaluar cuál es la contribución china específicamente para el fenómeno del aumento de los coeficientes de importación ocurrido en la mayor parte de los sectores de la actividad industrial de Brasil ${ }^{24}$ (Cuadro 6).

El Cuadro 6 muestra las cifras calculadas en el trabajo mencionado. En las dos primeras columnas están los valores que revelan la evolución de la participación de las importaciones (provenientes de todos los países) en el consumo aparente de los cuatro tipos definidos de productos, según el grado de intensidad tecnológica. En las dos columnas siguientes están expuestas específicamente las contribuciones de las importaciones de China para el consumo aparente brasileño, para cada tipo de producto. En la última columna, se evalúa también la contribución de China en la variación de la participación total de las importaciones brasileñas para el consumo aparente de cada tipo de producto. ${ }^{25}$

24 Los datos del Cuadro 6 no vienen directamente de los datos del Cuadro 5, pero están muy influenciados por ellos. En el Cuadro 6 es evaluada la participación porcentual de los productos importados (según la categoría del producto) en relación al consumo aparente. El consumo aparente permite calcular el llamado coeficiente de importación, indicador que describe cuánto del consumo interno es abastecido por importaciones netas: "para la composición de este indicador, fueron utilizados datos de comercio externo, originarios del Secex/MDIC, de la producción, obtenidos en la Encuesta Industrial Anual, e índices sectoriales de producción física y de precios, del IBGE, de la Funcex [todos los datos a precios del 2007] y de la Fundación Getúlio Vargas. Fueron calculados dos coeficientes de importaciones que difieren solamente en el numerador. El numerador del primero corresponde al total de las importaciones brasileñas, en cuanto el numerador del segundo refleja solamente las compras provenientes de China” (Puga y Nascimento, 2010: 3).

25 En el caso de los productos intensivos en tecnología, la contribución de las importaciones brasileńas provenientes de todos los demás países para el consumo aparente saltó de $29.0 \%$, en 2005, para 37.5\%, en 2010. En ese mismo periodo, la participación solamente de las importaciones chinas en el consumo aparente saltó de $4.4 \%$ para $9.8 \%$. Esto quiere decir que la contribución china saltó 5.4 puntos porcentuales, en un total de 8.5 puntos porcentuales $(37.5 \%$ menos 29.0\%). De esa manera, la contribución china para la variación, en puntos porcentuales, ocurrida en el conjunto de las importaciones brasileñas entre 2005 y 2010 (para los productos intensivos en tecnología) representó cerca de $63 \%$ de la variación total. En otras palabras: 5.4 puntos porcentuales en relación a un total de 8.5 puntos porcentuales. De la misma forma la contribución china para la variación total de la presencia de importaciones en el consumo aparente de productos intensivos en trabajo fue de casi $51 \%$, pues fue el resultado de una ampliación de cerca de 2.8 puntos porcentuales de la participación china sobre un total de 4.4 puntos porcentuales en la variación de la participación de las importaciones totales (saltó de $5.4 \%$ para $10.8 \%$, entre 2005 y 2010, considerando las importaciones provenientes de todos los países). Por lo mismo, obtenemos el resultado de $6 \%$ en el caso de los productos intensivos en recursos naturales y de $17 \%$ para los productos intensivos en escala. 
Amenazas y oportunidades del comercio brasileño con China

Cuadro 6. Coeficiente de importación por origen en \% del consumo aparente y contribución china en la variación entre 2005 y 2010

\begin{tabular}{|c|c|c|c|c|c|}
\hline & \multicolumn{2}{|c|}{ TOTAL } & \multicolumn{2}{|c|}{ CHINA } & \multirow{2}{*}{$\begin{array}{c}\text { China sobre } \\
\text { total }\left(^{\star}\right)\end{array}$} \\
\hline & 2005 & 2010 & 2005 & 2010 & \\
\hline INTENSIVOS EN RECURSOS NATURALES & 10.7 & 13.3 & 0.2 & 0.3 & 6.1 \\
\hline Extractiva & 46.2 & 55.5 & 0.1 & 0.1 & -0.7 \\
\hline Madera & 9.6 & 17.3 & 0.4 & 0.3 & -1.8 \\
\hline Alimentos y combustibles & 2.6 & 3.8 & 0.0 & 0.2 & 10 \\
\hline Prod. Madera & 1.9 & 2.3 & 0.1 & 0.4 & 80.5 \\
\hline Papel y celulosa & 5.3 & 8.5 & 0.0 & 0.4 & 12.4 \\
\hline Prod. Minerales no metálicos & 3.4 & 5.8 & 0.4 & 1.6 & 52.4 \\
\hline INTENSIVOS EN TRABAJO & 5.4 & 10.8 & 1.3 & 4.1 & 51.6 \\
\hline Textil & 7.8 & 17.8 & 2.1 & 7.5 & 54.8 \\
\hline Vestimenta & 2.4 & 6.7 & 1.1 & 4.0 & 68.7 \\
\hline Cueros y calzados & 4.5 & 7.2 & 2.0 & 3.6 & 58.6 \\
\hline Prod. de metal & 5.7 & 10.5 & 0.5 & 2.0 & 31.8 \\
\hline Muebles diversos & 5.8 & 9.6 & 2.4 & 5.6 & 83.6 \\
\hline INTENSIVOS EN ESCALA & 14.1 & 19.0 & 0.5 & 1.3 & 17.1 \\
\hline Químicos & 19.6 & 23.7 & 0.8 & 1.6 & 18.5 \\
\hline Caucho y plástico & 10.5 & 14.9 & 0.5 & 1.7 & 26.7 \\
\hline Metalurgia básica & 10.0 & 16.6 & 0.4 & 2.3 & 28.9 \\
\hline Vehículos & 10.1 & 16.5 & 0.1 & 0.4 & 4.8 \\
\hline INTENSIVOS EN TECNOLOGÍA & 29.0 & 37.5 & 4.4 & 9.8 & 63.3 \\
\hline Máquinas y equipos & 22.1 & 28.7 & 1.1 & 4.3 & 48.5 \\
\hline Material eléctrico & 34.2 & 50.3 & 7.8 & 19.6 & 73.7 \\
\hline Electrónicos & 35.7 & 50.4 & 7.4 & 16.5 & 62.2 \\
\hline Otros equip. transporte & 23.4 & 22.5 & 0.6 & 1.0 & -39.2 \\
\hline TOTAL & 14.2 & 19.8 & 1.1 & 2.9 & 32.4 \\
\hline
\end{tabular}

Fuente: CEXEC. Elaboración: APE/BNDES. Apud: Puga y Nascimento (2010).

${ }^{*}$ ) contribución porcentual china para la variación, en puntos porcentuales, Del coeficiente de importación entre 2005 y 2010. 
Fernando Augusto Mansor de Mattos y Marcelo Dias Carcanholo

En el Cuadro 6, se percibe claramente el aumento del coeficiente de importación en los cuatro tipos de productos seleccionados entre 2005 y 2010. Eso significa un aumento de la contribución de las importaciones en el consumo aparente brasileño, en cada tipo de producto. En términos porcentuales, el aumento más significativo se dio en los sectores intensivos en tecnología, y después en los sectores intensivos en trabajo y en escala. En el primero de esos tres casos, la contribución de las importaciones chinas para el aumento de la influencia de las importaciones (provenientes de todos los países) en el consumo aparente fue de casi 63\%; en el caso de los sectores intensivos en trabajo, la participación de las importaciones chinas fue de cerca de $51 \%$.

Lo que se concluye de estos datos es que la industria brasileña ha sido afectada por un proceso de creciente sustitución de la producción interna por productos importados. Esa sustitución en la demanda interna se manifiesta por el aumento de los productos importados en el consumo aparente de diversos sectores. En ese proceso, la contribución china ha crecido de forma importante en los años más recientes, y en dos de ellos su contribución para el aumento verificado en la economía brasileña de la participación de importaciones en el consumo aparente supera la contribución de todos los otros países del mundo. Esa creciente influencia de los importados chinos se expresa especialmente en los sectores intensivos en tecnología y en los sectores intensivos en trabajo (Cuadro 6). Ciertamente, esa gran penetración de los importados chinos ha tenido un impacto importante en el empleo industrial brasileño y también en la generación de valor en segmentos más sofisticados tecnológicamente y, por supuesto, de mayor valor agregado de la estructura industrial brasileña.

\section{EVOLUCIÓN COMPARADA DE LAS EXPORTACIONES CHINAS Y BRASILEÑAS EN EL MERCOSUR Y EN ALADI ${ }^{26}$}

En complemento a lo anterior se puede hacer un análisis adicional, destacando la influencia china en el comercio del Mercosur y de la ALADI, en comparación con la trayectoria de las exportaciones brasileñas para estos mismos bloques económicos. Ese análisis pude ser hecho con base en datos de COMTRADE en

26 Los datos para los cuadros de esta sección fueron obtenidos en el sito de CEPAL, con informaciones de COMTRADE. Ver: http://www.eclac.org/comercio/ecdata2/index.html. . Los datos de ALADI utilizados en este estudio se refieren siempre a ALADI 12, que incluye los siguientes países: Argentina, Brasil, Bolivia, Chile, Colombia, Cuba, Ecuador, México, Paraguay, Perú, Uruguay y Venezuela. 
internet que permiten una comparación de la evolución, en los últimos 10 años de las exportaciones chinas y brasileñas hacia el Mercosur (Cuadro 7) y a la ALADI (Cuadro 9), así como de la participación de cada una de ellas en el conjunto de importaciones de estos dos bloques económicos.

El Cuadro 7 revela para 2000, 2005, 2008, 2009 y 2010 el valor y la respectiva contribución porcentual de cada categoría de producto, en cada año, para el total de las exportaciones chinas y brasileñas para el Mercosur. De la misma forma el Cuadro 9 (más adelante) muestra los datos de las exportaciones chinas y brasileñas para la ALADI.

Cuadro 7. Exportaciones chinas y de Brasil para Mercosur por tipo de producto

Totales y porcentuales en cada año

2000 A 2010

años seleccionados

\begin{tabular}{|c|c|c|c|c|c|c|c|c|c|c|}
\hline & $\begin{array}{c}\text { valores } \\
\text { absolutos }\end{array}$ & $\begin{array}{l}\% \\
\text { año } \\
\end{array}$ & $\begin{array}{l}\text { valores } \\
\text { absolutos }\end{array}$ & $\begin{array}{l}\% \\
\text { año } \\
\end{array}$ & $\begin{array}{c}\text { valores } \\
\text { absolutos }\end{array}$ & $\begin{array}{l}\% \\
\text { año }\end{array}$ & $\begin{array}{c}\text { valores } \\
\text { absolutos }\end{array}$ & $\begin{array}{l}\% \\
\text { año } \\
\end{array}$ & $\begin{array}{l}\text { valores } \\
\text { absolutos }\end{array}$ & $\begin{array}{c}\% \\
\quad \text { año } \\
\end{array}$ \\
\hline CHINA & 2000 & 2000 & 2005 & 2005 & 2008 & 2008 & 2009 & 2009 & 2010 & 2010 \\
\hline Productos primarios & 33 & 1.53 & 92 & 1.38 & 231 & 0.90 & 172 & 0.91 & 431 & 1.30 \\
\hline $\begin{array}{l}\text { Basados en recursos } \\
\text { naturales }\end{array}$ & 256 & 11.85 & 1017 & 15.21 & 4564 & 17.79 & 2056 & 10.86 & 3495 & 10.56 \\
\hline De baja tecnología & 742 & 34.30 & 1379 & 20.63 & 5315 & 20.72 & 4316 & 22.79 & 8148 & 24.61 \\
\hline De tecnología media & 607 & 28.05 & 2169 & 32.43 & 8155 & 31.79 & 5982 & 31.59 & 10839 & 32.74 \\
\hline De alta tecnología & 524 & 24.24 & 2024 & 30.27 & 7353 & 28.66 & 6371 & 33.65 & 10131 & 30.61 \\
\hline Otras transacciones & 1 & 0.04 & 5 & 0.07 & 35 & 0.14 & 37 & 0.20 & 58 & 0.18 \\
\hline Total & 2163 & 100.00 & 6687 & 100.00 & 25653 & 100.00 & 18935 & 100.00 & 33102 & 100.00 \\
\hline BRASIL & 2000 & 2000 & 2005 & 2005 & 2008 & 2008 & 2009 & 2009 & 2010 & 2010 \\
\hline Productos primarios & 596 & 7.70 & 768 & 6.54 & 1479 & 6.80 & 888 & 5.61 & 1791 & 7.92 \\
\hline $\begin{array}{l}\text { Basados en recursos } \\
\text { naturales }\end{array}$ & 1434 & 18.53 & 1876 & 15.97 & 3825 & 17.60 & 2534 & 16.01 & 3330 & 14.73 \\
\hline De baja tecnología & 1396 & 18.04 & 1415 & 12.05 & 2526 & 11.62 & 1859 & 11.75 & 2539 & 11.23 \\
\hline De tecnología media & 3226 & 41.68 & 6302 & 53.65 & 11928 & 54.87 & 7722 & 48.78 & 12329 & 54.55 \\
\hline De alta tecnología & 1067 & 13.79 & 1363 & 11.60 & 1908 & 8.78 & 1710 & 10.80 & 2235 & 9.89 \\
\hline Otras transacciones & 21 & 0.27 & 22 & 0.18 & 70 & 0.32 & 1115 & 7.04 & 376 & 1.66 \\
\hline Total & 7740 & 100.00 & 11746 & 100.00 & 21737 & 100.00 & 15829 & 100.00 & 22600 & 100.00 \\
\hline
\end{tabular}

Fuente: CEPAL, con base en datos de Comtrade. 
El Cuadro 7 muestra que entre 2000 y 2005 las exportaciones chinas en dirección al Mercosur se triplicaron, en cuanto las brasileñas crecieron cerca de $50 \%$. Entre 2005 y 2010, las exportaciones chinas continuaron creciendo expresivamente. ${ }^{27}$ En el periodo completo (2000 a 2010), se puede constatar que las exportaciones chinas hacia el Mercosur cambiaron su composición, con un aumento de la participación de bienes de alta tecnología, en particular, y también de los de media tecnología en el total exportado por China al Mercosur.

Entre 2005 y 2010, las exportaciones brasileñas para el Mercosur doblaron, pero el crecimiento fue más intenso hasta 2008, con la disminución en el atípico año 2009, y retomando el crecimiento en 2010, que llega, asimismo, a un nivel poco superior al que había obtenido en 2008. Considerando todo el periodo entre 2000 y 2010 este crecimiento fue acompañado por una caída de la participación relativa de manufacturados de alta tecnología en el total exportado por Brasil (13.8\% en 2000 y $9.9 \%$ en 2010, aunque, en términos absolutos, tenga duplicado). ${ }^{28}$ Comparando los datos de 2009 con los del 2010 se constata una nueva pérdida de participación de los manufacturados de alto contenido tecnológico en su total (10.8\% y $9.8 \%$ respectivamente).

Las evoluciones de las exportaciones chinas y brasileñas, en términos de valores absolutos, muestran que entre 2005 y 2008 el valor de las primeras hacia el Mercosur superó el de las exportaciones brasileńas (Cuadro 7); en 2005 las exportaciones chinas de alta tecnología ya superaban a las brasileńas y, a partir de 2008 (por lo menos), las exportaciones chinas de baja y, principalmente, de alta tecnología, superaban en mucho a las brasileñas, a pesar del hecho de que los productos brasileńos pueden tener, dentro del Mercosur, en principio, un trámite más fácil que el de los productos chinos. La diferencia entre las exportaciones de manufacturados de media tecnología está disminuyendo rápidamente. ${ }^{29}$

27 Con una caída solamente en 2009 por los impactos de la crisis internacional sobre el volumen de comercio mundial y, también, sobre el ingreso de los países latinoamericanos. Entre 2005 y 2010 las exportaciones chinas con destino al Mercosur crecieron casi 5 veces.

28 En términos absolutos, entretanto, el valor de las exportaciones chinas de manufacturados de alta tecnología se multiplicó por 20 entre 2000 y 2010, llegando a un valor 5 veces mayor que el de Brasil para productos con este mismo grado de incorporación tecnológica.

29 La ventaja aún existente de las exportaciones brasileñas de media tecnología en relación a las chinas, se concentra específicamente en la industria automotriz instalada en Brasil, cuya tradición y magnitud del comercio externo con los países del Mercosur, así como con los de la ALADI, aún son bastante significativas. Asimismo, esa ventaja también ha disminuido en los años más recientes, una vez que ella fue de cerca de 4,2 mil millones de dólares en el conjunto de productos de media tecnología, en 2005, y estaba en apenas cerca de 1,5 mil millones de dólares en 2010. 
El Cuadro 8 evidencia que está en marcha una acelerada sustitución de productos brasileños por productos chinos en los mercados del Mercosur. Los datos revelan una ampliación considerable de productos chinos en las importaciones del Mercosur, saliendo de $0.8 \%$ en 1990 para 3.2\% en el ańo 2000, 13.2\% en 2008 y $16 \%$ en 2010 . Al mismo tiempo la participación brasileña que subía moderadamente entre 2000 y 2005, después de un salto en la década de 1990, empieza a caer entre 2005 y 2008, para volver a subir entre 2008 y 2010, y llegar en 2010 a un nivel inferior que el de China (12.4\% frente a 16\%). Igualmente preocupante, desde el punto de vista brasileño, es que la participación china ya supera en mucho a la brasileña en las manufacturas de alto y bajo contenido tecnológico, sin superar aún a la manufactura de media tecnología, en razón del vigor de las exportaciones automotrices de Brasil para la región.

Cuadro 8. Evolución de la participación relativa de productos chinos y brasileños en las importaciones del Mercosur por tipo de producto

1990-2010 años seleccionados

\begin{tabular}{lrrrrrr}
\hline CHINA & 1990 & 1995 & 2000 & 2005 & 2008 & 2010 \\
\hline Productos primarios & 1.3 & 0.4 & 0.5 & 0.7 & 0.8 & 1.6 \\
Basados en recursos naturales & 0.8 & 0.9 & 2.2 & 5.4 & 9.3 & 7.8 \\
De baja tecnología & 1.5 & 5.4 & 10.6 & 14.2 & 27.2 & 37.4 \\
De tecnología media & 0.3 & 1.0 & 2.1 & 5.2 & 9.1 & 11.8 \\
De alta tecnología & 0.5 & 1.0 & 4.2 & 14.2 & 25.1 & 31.1 \\
Otras transacciones & 0.0 & 0.3 & 0.6 & 1.3 & 4.6 & 17.9 \\
Total & 0.8 & 1.3 & 3.2 & 7.1 & 12.3 & 16.0 \\
\hline BRASIL & 1990 & 1995 & 2000 & 2005 & 2008 & 2010 \\
\hline Productos primarios & 2.5 & 5.3 & 6.2 & 5.5 & 4.9 & 7.1 \\
Basados en recursos naturales & 4.6 & 7.3 & 8.3 & 9.9 & 6.8 & 9.6 \\
De baja tecnología & 7.2 & 10.7 & 17.2 & 16.5 & 12.0 & 14.5 \\
De tecnología media & 6.6 & 8.5 & 10.9 & 16.0 & 13.0 & 18.3 \\
De alta tecnología & 1.9 & 2.1 & 5.2 & 6.7 & 4.6 & 6.2 \\
Otras transacciones & 0.4 & 1.7 & 1.8 & 8.2 & 9.3 & 8.8 \\
Total & 4.3 & 7.0 & 9.0 & 11.4 & 9.0 & 12.4 \\
\hline
\end{tabular}

Fuente: CEPAL, con base en datos de Comtrade. 
Fernando Augusto Mansor de Mattos y Marcelo Dias Carcanholo

El crecimiento de la presencia de productos chinos en las importaciones del Mercosur sugiere que la rivalidad de esos productos -mayormente en el caso de los manufacturados- con los productos brasileños se debe acentuar en ese bloque en los próximos años.

La situación es particularmente preocupante para Brasil justamente porque el Mercosur es un importante destino de las exportaciones de manufacturados brasileños. Ni el hecho mismo de ser parte del Mercosur y, por lo tanto, de poder disfrutar de las ventajas de esa membresía, ha impedido que las exportaciones brasileñas para ese bloque sufran creciente competencia de productos chinos.

Cuadro 9. Exportaciones de China y Brasil para ALADI ( $\left.{ }^{\star}\right)$ por tipo de producto

Totales y porcentuales en cada año

\begin{tabular}{|c|c|c|c|c|c|c|c|c|c|c|}
\hline \multicolumn{4}{|c|}{ selecionados } & \multicolumn{7}{|c|}{ valores en USS millones } \\
\hline & $\begin{array}{c}\text { valores } \\
\text { absolutos }\end{array}$ & $\begin{array}{l}\% \\
\text { año }\end{array}$ & $\begin{array}{l}\text { valores } \\
\text { absolutos }\end{array}$ & $\begin{array}{l}\% \\
\text { año }\end{array}$ & $\begin{array}{l}\text { valores } \\
\text { absolutos }\end{array}$ & $\begin{array}{c}\% \\
\text { año } \\
\end{array}$ & $\begin{array}{c}\text { valores } \\
\text { absolutos }\end{array}$ & $\begin{array}{c}\% \\
\text { S } \quad \text { año } \\
\end{array}$ & $\begin{array}{c}\text { valores } \\
\text { absolutos }\end{array}$ & $\begin{array}{r}\% \\
\text { s } \quad \text { año } \\
\end{array}$ \\
\hline CHINA & 0 & 2000 & 05 & 2005 & 0 & 2008 & 2009 & 2009 & 0 & 2010 \\
\hline $\begin{array}{l}\text { Producto } \\
\text { Basado }\end{array}$ & & 3 & 207 & & & 121 & 579 & 27 & & 12 \\
\hline & 7 & 10.42 & $t$ & 11.65 & 2 & 12.97 & 4432 & 3 & & 9 \\
\hline & & (1.01 & & & & & & & & 26.4 \\
\hline De tec & 1403 & 27.25 & & 8 & & 31 & 13292 & 29.17 & & 30.1 \\
\hline De alta & 24 & 19.8 & & 3 & & $2 \varepsilon$ & 0 & & & SL. \\
\hline Uilus I & 3 & & & & & & 7 & & & 0.2 \\
\hline-1 & 5151 & 10 & 975 & 0 & 7915 & 100.00 & 45574 & 100.00 & 9 & 100.0 \\
\hline & 00 & & & & & & & & & 201 \\
\hline $\begin{array}{l}\text { Productos } \\
\text { Basados }\end{array}$ & 23 & 7. & & & 1 & 13 & 3343 & 10 & 7 & 13.2 \\
\hline & & & & & & & & & & 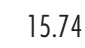 \\
\hline & & & & & & & & & & 11.2 \\
\hline & & & & & & & & & & 49.0 \\
\hline & & 12. & & & & & & & & \\
\hline Otras transacciones & 35 & 0.27 & 45 & 0.18 & 103 & & 1143 & 82 & & \\
\hline Total & 12916 & 100.00 & 25498 & 100.00 & 43095 & 100.00 & 29897 & 100.00 & 41201 & 100.0 \\
\hline
\end{tabular}

Fuente: CEPAL, con base de datos de Comtrade.

(*) considerados los siguientes países: Argentina, Brasil, Bolivia, Chile, Colombia, Cuba, Ecuador, México, Paraguay, Perú, Uruguay y Venezuela. 
El Cuadro 9 permite un análisis semejante al anterior, pero con datos relativos a los países de la ALADI ${ }^{30}$ que incluyen los del Mercosur y ocho países más. Como en el caso anterior se puede constatar la expansión de las exportaciones chinas entre 2000 y 2010 especialmente después de 2005. Los datos muestran que hubo un salto en las exportaciones chinas, en especial de bienes industrializados de baja y de alta tecnología. Así como ocurrió en el caso del Mercosur como destino, también ya en 2005 las exportaciones chinas en esos dos tipos de productos industrializados superaban las exportaciones de Brasil cuando se trata de la ALADI como destino. La diferencia, en este caso, es que, las exportaciones chinas de bienes manufacturados de media tecnología también superan a las de Brasil.

Una señal evidente de que las ventajas institucionales disfrutadas por Brasil en el Mercosur han podido evitar una mayor expansión de la presencia de productos chinos en aquel mercado, es que en 2008 por ejemplo, el total de exportaciones chinas en la ALADI representaba $34 \%$ superior al valor de las exportaciones brasileñas, en cuanto en el Mercosur representaban 18\% más que las brasileñas. Parte de la explicación para esta diferencia también puede estar en los tratados comerciales celebrados recientemente por Perú y Chile con el país asiático, ampliando su presencia en la ALADI. Finalmente, la importancia relativa de productos chinos y brasileños, tanto en Mercosur, como en la ALADI, permite concluir una creciente competencia entre Brasil y China en estos mercados.

Los datos del Cuadro 10 están organizados de la misma forma que los datos del Cuadro 8, sólo que con informaciones de la ALADI; revelan situaciones parecidas a las descritas para Mercosur pero con mayor claridad en algunos tipos de productos, ya que la inserción china en la ALADI es mayor que en Mercosur, además de que, obviamente, el mercado es más amplio. Las estadísticas reveladas por el Cuadro 10 demuestran que en 2008 la participación de productos importados de China en esos países era más de dos veces mayor que la de los productos brasileńos, lo que hace especialmente significativa la ventaja disfrutada por manufacturas de alto contenido tecnológico así como en los tradicionalmente presentes productos manufacturados de bajo contenido de tecnología, cuya participación además ha aumentado partiendo de una base expresiva en la mitad de la década.

30 Los datos del Cuadro 9 fueron obtenidos con base en informaciones correspondientes a las importaciones de la ALADI, y no sobre la perspectiva de China. Las diferencias, entretanto, no son muy grandes cuando se utilizan los datos desde la perspectiva china en esta publicación. 
Fernando Augusto Mansor de Mattos y Marcelo Dias Carcanholo

Cuadro 10. Evolución de la participación relativa de productos chinos y brasileños en las importaciones de ALADI por tipo de producto

1990-2010 años seleccionados

\begin{tabular}{lrrrrrr}
\hline CHINA & 1990 & 1995 & 2000 & 2005 & 2008 & 2010 \\
\hline Productos primarios & 0.8 & 0.4 & 0.9 & 0.9 & 0.8 & 1.4 \\
Basados en recursos naturales & 0.5 & 0.8 & 1.7 & 3.6 & 5.7 & 5.4 \\
De baja tecnología & 1.9 & 3.5 & 5.8 & 12.5 & 21.7 & 22.4 \\
De tecnología media & 0.4 & 0.8 & 1.7 & 5.2 & 8.6 & 9.8 \\
De alta tecnología & 0.7 & 1.1 & 2.8 & 15.3 & 24.1 & 32.0 \\
Otras Transacciones & 0.1 & 0.2 & 1.1 & 6.2 & 6.2 & 14.0 \\
Total & 0.7 & 1.2 & 2.4 & 7.5 & 11.5 & 14.8 \\
\hline BRASIL & 1990 & 1995 & 2000 & 2005 & 2008 & 2010 \\
\hline Productos primarios & 2.1 & 3.3 & 3.7 & 4.8 & 6.2 & 1.6 \\
Basados en recursos naturales & 3.3 & 5.1 & 4.6 & 5.4 & 4.3 & 2.2 \\
De baja tecnología & 4.8 & 5.6 & 4.5 & 5.8 & 5.8 & 2.5 \\
De tecnología media & 5.3 & 5.5 & 5.1 & 8.8 & 7.8 & 3.4 \\
De alta tecnología & 2.0 & 1.6 & 2.3 & 3.4 & 3.3 & 1.0 \\
Otras Transacciones & 1.5 & 0.9 & 0.4 & 4.7 & 3.8 & 5.9 \\
Total & 3.7 & 4.4 & 4.0 & 6.2 & 5.7 & 2.4 \\
\hline
\end{tabular}

Fuente: CEPAL, con base en datos de Comtrade.

$\left.{ }^{(}\right)$considerados los siguientes países: Argentina, Brasil, Bolivia, Chile, Colombia, Cuba, Ecuador, México, Paraguay, Perú, Uruguay y Venezuela.

Datos del 2010 revelan que la retomada de la actividad económica ocurrida en China y en los países latinoamericanos permitió que las exportaciones chinas continuasen ganando espacio en las importaciones de la ALADI, saliendo de $11.5 \%$ para $14.8 \%$, aumentando la diferencia con la participación brasileña, que cae rápidamente entre 2008 y 2010, año en el que se queda con apenas $2.4 \%$ del total de importaciones de la ALADI. La pérdida de participación brasileńa fue muy importante en todos los tipos de productos, con más destaque para los manufacturados de alto contenido tecnológico. ${ }^{31}$

31 Esa caída, en principio, llama la atención. Investigando con más detalles los demás datos de comercio externo de Comtrade esa trayectoria se confirma. Aunque es un año atípico en 2009 ya se apuntaba para esa caída, con Brasil representando apenas 5.3\% de las 


\section{CONCLUSIONES}

No se puede negar que la reciente ampliación del comercio externo con China ha tenido efectos benéficos en el corto plazo para la actividad económica de Brasil. Todavía hay fuertes señales de que la expansión de las exportaciones chinas ha afectado el desempeño de las exportaciones brasileñas en otros mercados, así como a la propia producción manufacturera brasileña, crecientemente sustituida por productos chinos en la demanda doméstica.

China ha penetrado en todos los mercados mundiales desplazando ventas de diversos países y bloques económicos en otros mercados de todo el mundo (Pasin, 2010). Lo que preocupa en el caso brasileño es que en América del Sur, y especialmente en Brasil, este movimiento parece que ha sido más fuerte que en otras partes (hay crecimiento por encima del promedio mundial). Además, las estructuras productivas de Brasil y China son concurrentes en diversos sectores industriales, razón por la cual Brasil necesita estrategia y planificación para enfrentar el reciente cambio de la realidad promovido por la expansión de las exportaciones chinas en todos los continentes, y también en su propio mercado interno.

Las estadísticas analizadas mostraron una fuerte congruencia entre los datos investigados y organizados en la primera y segunda partes de este trabajo con aquellos que fueron organizados en la tercera y cuarta partes. En otras palabras, los resultados obtenidos con el cruce de datos confirman y refuerzan, con nuevas

importaciones de ALADI 12. Analizando la evolución de las importaciones de algunos países seleccionados, se puede verificar, por ejemplo, que, entre 2008 y 2010, en mil millones de dólares, las importaciones mexicanas provenientes de Brasil cayeron de 5.1 a 4.3 y las peruanas de 2.4 a 2.1. También hubo caídas de la presencia brasileña en las importaciones ecuatorianas y colombianas, aunque no tan expresivas. En los casos de Argentina y Chile, no había acceso a los datos aislados para estos países en el ańo 2010. Por otro lado, las informaciones de importaciones -obtenidas del punto de vista de los países latinoamericanos- en la referida base de datos revelan una significativa ampliación de la presencia de productos chinos en México (aumento de 34.7 mil millones de dólares en 2008 para 45,6 mil millones de dólares en 2010) y aumento importante también en Perú y Colombia. Finalmente, tomando las informaciones desde el punto de vista de las exportaciones de Brasil y China, la base de datos muestra que las exportaciones chinas para ALADI 12, en 2005, sumaban casi 18 mil millones de dólares y eran inferiores a las brasileñas para el mismo destino, que sumaban casi 25,5 mil millones de dólares. En 2008, todavía, las exportaciones chinas ya sumaban casi 58 mil millones de dólares, y las brasileńas poco más de 43 mil millones de dólares. En 2010, las chinas estaban en 72,7 mil millones de dólares, y las brasileñas en 41,2 mil millones de dólares. 
evidencias y nuevos argumentos, conclusiones sacadas por otros autores nombrados en este estudio.

Los datos relacionados a las exportaciones hacia el Mercosur sugieren que Brasil puede estar perdiendo mercado en ese bloque económico para los concurrentes chinos, notablemente en los sectores más intensivos en tecnología, y también en los de baja tecnología (muchas veces intensivos en trabajo). Se debe registrar que Brasil mismo, al ser integrante de Mercosur, está recibiendo también esa fuerte entrada de productos importados que vienen de China. Hay indicios muy claros de que la fuerza de las exportaciones chinas ha debilitado las posibilidades de inserción de las exportaciones brasileñas tanto en Mercosur como en la ALADI, lo que representa una situación preocupante para Brasil.

Esa deficiencia en la competitividad brasileña, incluso en regiones vecinas al país, evidencia los problemas brasileños en términos de infraestructura y demuestra el hecho de que China tenga un modelo de desarrollo económico apoyado en políticas de inversiones públicas en infraestructura, en presencia de empresas estatales en actividades exportadoras estratégicas, en política industrial de impulso efectivo a los sectores más intensivos en tecnología, y Brasil no tiene algo semejante. Termina produciendo resultados también diferentes en términos de inserción en el comercio internacional.

Además, el tipo de cambio brasileño, excesivamente evaluado ya hace muchos años profundiza las dificultades estructurales del país en generar diferenciales de productividad en la actividad económica. Los pocos sectores que han logrado avances de productividad, en general, se han apoyado en estrategias producidas por reducción del empleo y/o por incrementos marginales en términos de reducción de costos salariales, posibilitados por un mercado de trabajo excesivamente flexible a favor del capital. No ha habido, por lo tanto, mejoras considerables en la productividad que sean obtenidas por elevados aportes en inversiones de ciencia y tecnología, en una estrategia de innovaciones.

El gobierno brasileño ha reconocido las dificultades de las actividades industriales, especialmente en la competencia en el escenario externo y, recientemente, ha lanzado un paquete de medidas ${ }^{32}$-generosamente auto-intitulado de "política industrial"- que, en verdad, trata superficialmente algunos de los elementos relativos a la competitividad industrial y a las preocupaciones con la reprimarización de las exportaciones brasileñas. Este paquete no es más que una lista de intenciones, sin mucho efecto práctico, tanto por no poseer medidas que

32 Consultar el llamado "Plano Brasil Maior" en el sitio del Ministerio del Desarrollo: http:// www.brasilmaior.mdic.gov.br/oplano/medidas/ 
efectivamente cambien los dos precios más importantes de la economía (tasa de interés y tipo de cambio, ambas interdependientes y, en los niveles que se encuentran actualmente, desfavorables para la producción, el empleo y la competitividad industrial), cuanto también por no indicar cambios importantes en el sistema nacional de innovaciones tecnológicas, en las actividades industriales estratégicas, y en la ampliación en las inversiones públicas en infraestructura.

Este trabajo permite concluir que el marcado crecimiento del comercio externo, especialmente con el mercado latinoamericano, aumentará la competencia entre la producción industrial brasileńa y los productos manufacturados chinos. China, como una economía gigante, y al mismo tiempo, la más dinámica del mundo en este momento, tiende a continuar promoviendo, más que cualquier otro país o al igual que cualquier otro bloque económico cambios profundos en la composición de las importaciones y exportaciones de Brasil, una vez que hay muchas actividades en que las estructuras productivas de los países son concurrentes. Además, como vimos, Brasil aún no logró construir una estrategia económica y un nuevo arreglo político interno para enfrentar de hecho las cuestiones relacionadas a su pérdida de competitividad en el escenario del comercio internacional. Se debe subrayar también que la expansión china continuará afectando los perfiles del comercio externo de todos los demás países latinoamericanos.

Lo que también quedó claro es que tanto en los sectores en que China incrementó su competitividad histórica (como en los sectores intensivos en trabajo), como en los que ella construyó ${ }^{33}$ en las tres últimas décadas (por lo menos), una creciente competitividad externa (como en los casos de sectores intensivos en tecnología y en los sectores intensivos en escala), los efectos sobre la actividad industrial brasileña han sido impactantes. Esos efectos se manifiestan tanto en lo que se refiere a la penetración de los importados chinos en el mercado interno brasileño, ampliando de manera significativa su peso en el consumo aparente brasileño, como al restringir el mercado externo para exportados brasileños de ciertos sectores industriales. En ese sentido, hubo clara coincidencia, como mencionamos antes, entre los datos organizados en las dos primeras secciones de este estudio y los datos destacados en la tercera y cuarta partes.

Esa diferencia de desempeño entre China y Brasil es función directa de la ya mencionada falta de estrategia brasileña, manifiesta en la ausencia de inversiones públicas en infraestructura, de una acción más efectiva en el escenario

33 Sobre la estrategia de desarrollo económico chino en las últimas décadas ver: Medeiros (2006; 2010); Oliveira (2005), entre otros. 
Fernando Augusto Mansor de Mattos y Marcelo Dias Carcanholo

geopolítico internacional, y de algo próximo a un sistema nacional de innovaciones, factores éstos que sumados limitan los logros de productividad de la actividad económica y, por lo tanto, de competitividad de la industria brasileńa en el escenario internacional.

\section{BIBLIOGRAFÍA}

Baumann, R. (org.), O Brasile os demais BRICs-comércio e politica, CEPAL-IPEA, 2010.

Baumann, R., R. Araujo, J. Ferreira, As relaçôes comerciais do Brasil com os demais BRICs, In: Baumann, R. (org.), (2010).

CEPAL, La República Popular China y América Latina y El Caribe: hacia una relación estratégica, Santiago, CEPAL, 2010.

Felipe, P. C. N., O Sonho do Quarto Vermelho: revolução e reformas na China contemporânea, Dissertaçáo de Mestrado defendida no Programa de PósGraduação em Economia, UFF, Niterói, 2009.

Gonçalves, R., "Competitividade Internacional e Integração Regional: a hipótese da inserção regressiva", Revista de Economia Contemporânea, Rio de Janeiro, vol. 5 (ediçâo especial), 2001.

Gonçalves, R., M. D. Carcanholo, L., Filgueiras, y E. Pinto, "Vulnerabilidad estructural externa en América Latina”, Em: Arceo, E. y E. Basualdo (Comps.), Los condicionantes de la crisis en América Latina: inserción internacional y modalidades de acumulación, Buenos Aires, Clacso Libros, 2009.

Macedo e A. C. Silva, "O Expresso do Oriente: redistribuindo a produção e o comércio globais", Observatório da Economia Global, textos avulsos, núm. 2, abril, 2010. CECON-Unicamp.

Medeiros, C.A. "A China como um Duplo Pólo na Economia Mundial e a Recentralização da Economia Asiática”, Revista de Economia Politica, vol. 26, núm. 3 (103), , julho-setembro, 2006, pp. 381-400.

Medeiros, C. A., "O ciclo recente de crescimento chinês e seus desafios", Observatório da Economia Global, Textos avulsos, núm. 3, CECON/UniCAMP, junho, 2010.

Nascimento, C. A., S. A. Cardozo, K. L. Nascimento, O sentido da reprimarização da pauta exportadora: uma interpretação à luz de Celso Furtado, Caio Prado Jr. e Francisco de Oliveira, In: Xuvi Congresso da Sociedade Brasileira de Economia, Administraçáo e Sociologia Rural (sober), Rio Branco (AC), 2008.

Oliveira, C. A. B. "Reformas Econômicas na China", Economia Política Internacional, CERi/IE/UniCAMP, Campinas, núm. 7, pp. 12-23, abr.jun. 2005. 
Pasin, J. A. "Impactos da abertura comercial chinesa sobre o comércio internacional (1998-2006)", Revista do BNDES, vol. 14, núm. 29, pp. 309-326, jun/2008.

Puga, F. y M. Nascimento, "O efeito China sobre as importaçôes brasileiras", BNDES, Visão do Desenvolvimento, núm. 89, Dez/2010.

Sawaya, R. R. "China: uma estratégia de inserção no capitalismo mundial”, Revista da Sociedade Brasileira de Economia Política, sep, São Paulo, núm. 28, fevereiro. 2011, pp. 5-35.

SELA. Evolución reciente de las relaciones económicas entre la República Popular de China y América Latina y El Caribe. Mecanismo institucionales y de cooperación para su fortalecimiento, Xxxvi Reunión Ordinaria del Consejo Latinoamericano, Caracas, Venezuela, 27 al 29 octubre de 2010.

Thorstensen, V., China, lider das exportaçóes mundiais e também membro da OMC: desafios e oportunidades para o Brasil, vII Fórum de Economia da FGV-SP, 2010. Acceso: http://www.eesp.fgv.br/_upload/noticia/4c9770fd75b6c.pdf 